Research Paper

\title{
Effects of long-term fertilization on the diversity of bacterial mercuric reductase gene in a Chinese upland soil
}

\author{
Yu-Rong Liu, Ji-Zheng He, Li-Mei Zhang and Yuan-Ming Zheng \\ State Key Laboratory of Urban and Regional Ecology, Research Center for Eco-Environmental Sciences, \\ Chinese Academy of Sciences, Beijing, China
}

Soil mercury (Hg) pollution has received considerable attention due to its neurotoxin effects and its potential risk to food safety. The microbial transformation of Hg plays a key role in reducing Hg toxicity by the mercuric reductase (MerA) conferred by genes arranged in the mer operon. This study investigated the effects of long-term fertilization on the diversity of bacterial mercuric reductase gene (merA), which specify the reduction of ionic $\mathrm{Hg}^{2+}$ to the volatile elemental form $\mathrm{Hg}^{0}$, in an agricultural soil with relatively high $\mathrm{Hg}$ content. The soil samples were collected from different treatments, including control without fertilizer (CK), fertilizer nitrogen $(\mathrm{N})$, combined fertilizers $(\mathrm{NPK})$ of $\mathrm{N}$, phosphorus $(\mathrm{P})$ and potassium $(\mathrm{K})$, and NPK plus organic manure (NPK + OM). The merA gene diversity patterns were analyzed based on the merA clone libraries and sequencing measurements. Results showed that the merA gene diversity was influenced by soil variables depending on the fertilization practices. In particular, $\mathrm{NH}_{4}^{+}$and $\mathrm{NO}_{3}^{-}$contents had strong effect on the merA gene diversity pattern both in the $\mathrm{N}$ and NPK treatments, whereas the merA gene diversity pattern in NPK + OM treatment was distinctly influenced by the contents of organic matter, available $\mathrm{P}$ and $\mathrm{K}$. These results suggested that long-term fertilization had significant influences on merA gene diversity, which could be helpful to understand the $\mathrm{Hg}$ reduction process and potentially serve microbial remediation of Hg contaminated soil.

Keywords: Soil / Mercury / merA gene / Diversity / Fertilization

Received: April 27, 2011; accepted: July 21, 2011

DOI 10.1002/jobm.201100211

\section{Introduction}

For decades, mercury (Hg) pollution has received considerable attention due to its neurotoxin effects and its ability to biomagnify in the food chains [1-2]. The fate of $\mathrm{Hg}$ in soil depends upon lots of environmental factors related to physical, chemical and biological processes. Among them, the microbial transformation plays a critical role in modulating the toxicity of $\mathrm{Hg}$ through reducing ion $\mathrm{Hg}^{2+}$ into the volatile and less toxic element $\mathrm{Hg}^{0}$ [3-5]. Indeed, this biochemical process is usually controlled by the mercuric reductase (MerA)

Correspondence: Yuan-Ming Zheng, State Key Laboratory of Urban and Regional Ecology, Research Center for Eco-Environmental Sciences, Chinese Academy of Sciences, 18 Shuangqing Road, Beijing 100085 Beijing, China

E-mail: zhengym@ rcees.ac.cn

Phone: 86-10-62849500

Fax: 86-10-62849500 conferred by genes arranged in the mer operon as a resistance mechanism to $\mathrm{Hg}$ [6-8]. It was a critically important detoxification process as evidenced by the resumption of microbial growth after the removal of gaseous form of element $\mathrm{Hg}^{0}[9,10]$. And thus, the merA gene has been studied as a relevant functional gene for understanding the microbial transformation of $\mathrm{Hg}$ speciation in environments.

Mercury resistance genes (merA) are often carried on plasmids or other mobile genetic elements [11, 12], which are widely spread in bacteria from diverse environments [13-17]. The bacteria that exposed to the long-term selective stress would probably be resistant, and thus leading to high merA diversity [18]. A high diversity of merA gene sequences was detected in an anaerobic mercury-contaminated sediment [19], which exhibited distinct differences of the merA sequences from other aerobic environments. Various merA diver- 
sity patterns were also detected along floodplain soil profiles [18], and even in the high Arctic area [10], suggesting the potential of $\mathrm{Hg}$ reduction by Hg-resistance microorganisms in very diverse environments. The merA genes were showing high diversities along with the variation of the environment. Additionally, Ramond et al. [20] reported that human activity could be a determining factor in the occurrence of the gramnegative merA gene in mudflat sediments. As we know, soil is a complex medium attributed with complicated physical and chemical properties, as well as strong disturbance from human activities, but little is known about the effects of anthropogenic factors, especially long-term fertilization practices, on merA gene diversity in agricultural soils.

Fertilization, as a common and important agricultural management practice, can provide essential nutrients for crop growth, and support a diverse and active microbial community [21]. Some studies have provided general appreciation of effects of fertilization on soil bacteria [18, 22]. Consequently, long-term fertilization practices could result in significant shifts in the abundance and community composition of soil functional microorganisms, such as ammonia oxidizers, methanotrophs and sulfate reducing prokaryotes [2224]. However, knowledge of the effect of long-term fertilization on the merA gene diversity is particularly scarce. Previous study has reported the potential $\mathrm{Hg}$ pollution soil with long-term fertilization in the Qiyang experimental station, Hunan Province, China [25]. The $\mathrm{Hg}$ in this soil was mainly originated from soil parent materials but not an anthropogenic input. And the crop grown in this soil accumulated higher concentration of $\mathrm{Hg}$ beyond the hygienic standard for grains $\left(0.02 \mathrm{mg} \mathrm{kg}^{-1}\right)$ indicating food chain health risk. The purpose of the present study was to examine the effects of long-term different fertilization practices on the merA gene diversity, and the obtained data would be helpful to the microbial remediation of $\mathrm{Hg}$ contaminated.

\section{Materials and methods}

\section{Study site and sampling}

The site was located at Qiyang Red Soil Experimental Station $\left(26^{\circ} 45^{\prime} \mathrm{N}, 111^{\circ} 52^{\prime} \mathrm{E}\right)$, Hunan Province, China. A long-term fertilizer experiment was established in 1990 with a wheat-maize rotation system. The top soil (0$20 \mathrm{~cm}$ ) samples were collected from the experimental plots, including four treatments with three replicates: control without fertilizers $(\mathrm{CK})$; chemical fertilizer nitrogen $(\mathrm{N})$; combined chemical fertilizers (NPK) of $\mathrm{N}$, phosphate $(\mathrm{P})$ and potassium $(\mathrm{K})$ and NPK plus organic manure (NPK + OM). The soil had high background concentration of $\mathrm{Hg}$ and potential environmental risk according to the previous study [25]. Basic soil characteristics are listed in Table 1 . Soil samples were passed through a $2.0 \mathrm{~mm}$ sieve, and stored at $-80^{\circ} \mathrm{C}$ for DNA extraction.

\section{Soil DNA extraction and purification}

DNA was extracted from $0.5 \mathrm{~g}$ fresh soil sample using Ultra-clean $^{\mathrm{TM}}$ soil DNA Isolation Kits (MoBio Laboratory, USA) according to the manufacturer's protocol. The quality of extracted DNA was evaluated on a $1 \%$ agarose gel and the concentration and purity of the extracts were estimated by a spectrophotometer (NanoDrop, USA).

\section{PCR application and construction of merA library}

The presence of merA gene in the DNA extracts was detected by a nested PCR approach as attempts to directly amplify the merA gene from the soil DNA extracts had been unsuccessful. A 1,250 bp fragment was amplified as follows: 15 cycles of $10 \mathrm{~s}$ at $94^{\circ} \mathrm{C}, 45 \mathrm{~s}$ at $54^{\circ} \mathrm{C}$, and $30 \mathrm{~s}$ at $72^{\circ} \mathrm{C}$, using the forward primer A2-n.F (5'CCATCGGCGGCWCYTGCGTSAA- $3^{\prime}$ ) and the reverse primer A5-n.R (5'-ACCATCGTCAGRTARGGRAAVA-3') [10]. The obtained PCR products were separated by $1 \%$ agarose gel electrophoresis, excised, purified using a gel

Table 1. Chemical properties of the Chinese upland red soil under different fertilization regimes ${ }^{a}$.

\begin{tabular}{|c|c|c|c|c|c|c|c|}
\hline & $\begin{array}{l}\mathrm{pH}^{\mathrm{b}} \\
\left(\mathrm{H}_{2} \mathrm{O}\right)\end{array}$ & $\begin{array}{l}\text { Organic matter } \\
(\%)\end{array}$ & $\begin{array}{l}\mathrm{NH}_{4}^{+}-\mathrm{N} \\
\left(\mathrm{mg} \mathrm{kg}^{-1}\right)\end{array}$ & $\begin{array}{l}\mathrm{NO}_{3}^{-}-\mathrm{N} \\
\left(\mathrm{mg} \mathrm{kg}^{-1}\right)\end{array}$ & $\begin{array}{l}\text { Available } P \\
\left(\mathrm{mg} \mathrm{kg}^{-1}\right)\end{array}$ & $\begin{array}{l}\text { Available K } \\
\left(\mathrm{mg} \mathrm{kg}^{-1}\right)\end{array}$ & $\begin{array}{l}\text { Total } \mathrm{Hg}^{\mathrm{c}} \\
\left(\mathrm{mg} \mathrm{kg}^{-1}\right)\end{array}$ \\
\hline CK & $5.47 \pm 0.18$ & $1.36 \pm 0.06$ & $19.1 \pm 0.61$ & $5.1 \pm 1.54$ & $30.1 \pm 2.3$ & $29.4 \pm 2.1$ & $0.64 \pm 0.13$ \\
\hline $\mathrm{N}$ & $3.71 \pm 0.15$ & $1.52 \pm 0.29$ & $21.0 \pm 5.84$ & $43.6 \pm 7.7$ & $4.4 \pm 3.1$ & $16.9 \pm 3.3$ & $0.60 \pm 0.09$ \\
\hline NPK & $4.04 \pm 0.06$ & $1.69 \pm 0.08$ & $28.8 \pm 2.40$ & $8.7 \pm 2.7$ & $51.3 \pm 4.2$ & $85.7 \pm 2.5$ & $0.54 \pm 0.07$ \\
\hline $\mathrm{NPK}+\mathrm{OM}$ & $5.81 \pm 0.15$ & $2.13 \pm 0.08$ & $17.7 \pm 1.24$ & $18.7 \pm 4.0$ & $137.0 \pm 3.5$ & $19.0 \pm 3.8$ & $0.51 \pm 0.09$ \\
\hline
\end{tabular}

${ }^{a}$ treatments include: control without fertilizers (CK); chemical fertilizer nitrogen (N); combined chemical fertilizers (NPK) of N, phosphate $(\mathrm{P})$ and potassium $(\mathrm{K})$ and NPK plus organic manure (NPK + OM).

b data is from reference 23.

${ }^{c}$ data is from reference 25 . 
purification kit (Promega), and diluted as templates for the second PCR with the forward primer A7s-n.F (5'CGATCCGCAAGTGGCIACBGT-3') and the reverse primer A5-n.R (5'-ACCATCGTCAGRTARGGRAAVA-3') [4]. In this reaction, a $291 \mathrm{bp}$ fragment internal to the $1,250 \mathrm{bp}$ template was amplified as follows: 40 cycles of $10 \mathrm{~s}$ at $94{ }^{\circ} \mathrm{C}, 45 \mathrm{~s}$ at $54{ }^{\circ} \mathrm{C}$, and $30 \mathrm{~s}$ at $72{ }^{\circ} \mathrm{C}$. The final PCR products (291 bp) were confirmed by a $1 \%$ agarose gel electrophoresis and purified with a gel purification kit (Promega). Afterward, twelve merA clone libraries, consisting of the replicates samples from each of the four soil treatments, were constructed.

\section{Sequencing and phylogenetic analysis}

A total of 408 clones in the twelve libraries were single strand sequencing. Representative merA gene sequences were deposited in the GenBank nucleotide sequence database under Accession No. GU367623-GU367653. The merA nucleotide sequences were trimmed and assembled using SeqMan (DNAStar, Madison, WI). Homology analysis of the merA sequences was performed using the software DNAMAN version 4.0 (Lynnon Biosoft, USA). Sequences displaying more than 95\% identity with each other were grouped into the same operational taxonomic units (OTUs). Phylogenetic analysis was performed using MEGA version 4.0 and the neighbor-joining tree was constructed using the Poisson correction model with Bootstrap value of 1000 .

\section{Data analysis}

Evaluation of the clone libraries was performed by a rarefaction analysis using software aRarefactWin Version 1.3 (Steven Holland, Stratigraphy Lab, University of Georgia [http://www.uga.edu/strata/software/Software. html]. The Shannon index was calculated based on the following equation: $H^{\prime}=-\Sigma p i \ln (p i)$, where $H^{\prime}=$ ShannonWiever diversity index, $p i=n i / \mathrm{N}, n i$ is the abundance of the OTU, $\mathrm{N}$ is the total abundance of all OTUs in the sample. Non-parametric richness estimates (Chao 1) were calculated according to the previous literature [26]. The similarity of phylogenetic compositions of merA clone libraries between different treatments were compared using the Sorensen similarity index, $C s=$ $2 j /(a+b)$, in which $\mathrm{j}$ is the number of common OTUs in two merA clone libraries of different treatments, a and $\mathrm{b}$ are the numbers of OTUs in the two libraries, respectively [27].

The differences of merA gene diversity patterns among the four fertilization regimes were statistically analyzed using one-way analysis of variance (ANOVA). All these statistics were conducted using SPSS software. Canonical correspondence analysis (CCA) (Canoco 4.5 for Windows) was performed to explore the relationship between environmental variables and the merA gene diversity in the twelve clone libraries [28]. Variables to be included in the model were chosen by forward selection at 0.05 baseline. Test significance of the constrained ordination process was tested with the Monte Carlo permutation test.

\section{Results}

\section{Analysis of merA clone libraries}

Estimates of merA gene diversity in the four treatments, based on the sequenced clones, are shown in Table 2. All of the merA gene libraries were sampled adequately as the rarefaction curves approached a plateau (Fig. 1). The relatively high OTU number was observed in the $\mathrm{N}$ treatment, in which the value of richness (Chao 1) was significantly higher than those in the other treatments. No significant difference was found in Shannon index among the four treatments.

The Sorensen similarity index was used to identify the similarity of merA library compositions between the treatments, ranging from 0 to $75 \%$ in the four treatments (Table 3 ). The relatively high Sorensen similarity index was found between the N and NPK treatments, indicating that they had very similar merA clone library composition. The NPK + OM treatment had relatively lower values of $0,27 \%$ and $15 \%$ compared with CK, $\mathrm{N}$ and NPK treatments, suggesting its library composition was distinctly different from the compositions of other merA clone libraries.

Table 2. Diversity analysis of merA gene fragment libraries.*

\begin{tabular}{lllll}
\hline & No. of sequences & OTU (95\%) & Chao 1 & H' $^{\prime}$ \\
\hline CK & 102 & 14 & $8.4(7.1-9.1)^{\mathrm{a}}$ & $1.1(0.9-1.2)^{\mathrm{a}}$ \\
N & 102 & 16 & $11.4(10.9-11.8)^{\mathrm{b}}$ & $1.6(1.1-1.9)^{\mathrm{a}}$ \\
NPK & 102 & 12 & $8.6(6.1-11.1)^{\mathrm{a}}$ & $1.2(0.7-0.6)^{\mathrm{a}}$ \\
NPK + OM & 102 & 10 & $7.4(6.2-9.1)^{\mathrm{a}}$ & $1.2(1.2-1.3)^{\mathrm{a}}$ \\
\hline
\end{tabular}

* Chao1, Chao1 nonparametric richness estimate; $\mathrm{H}^{\prime}$, Shannon-Weaver diversity index; Values within the same column followed by the same letter do not differ at $P<0.05$. 


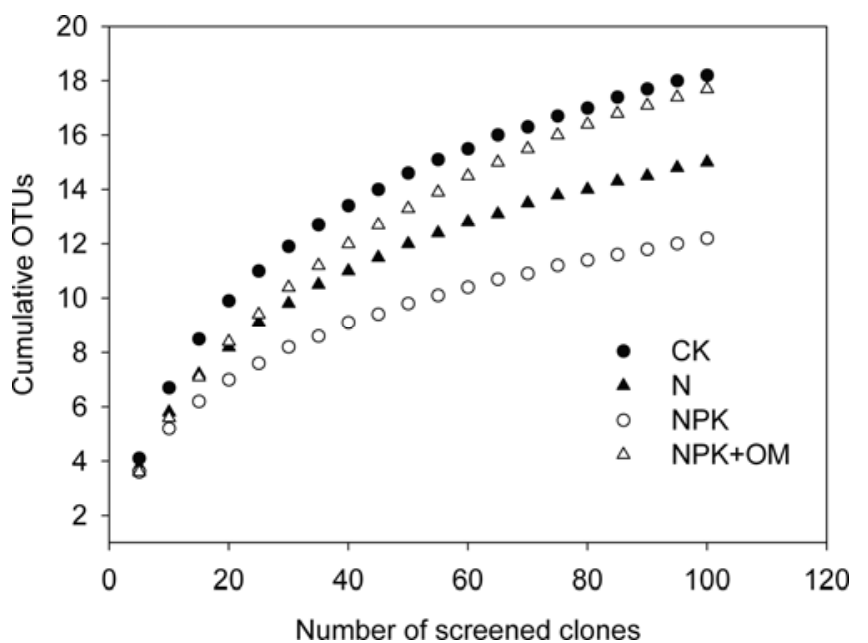

Figure 1. Rarefaction analysis of the merA clones obtained from soils with the different fertilization treatments using software aRarefactWin Version 1.3. Treatment: control without fertilizers (CK); chemical fertilizer nitrogen $(\mathrm{N})$; combined chemical fertilizers (NPK) of N, phosphate $(\mathrm{P})$ and potassium $(\mathrm{K})$ and NPK plus organic manure $(\mathrm{NPK}+\mathrm{OM})$.

\section{Effects of soil environmental variables on the merA gene diversity}

The Canonical Correspondence Analysis (CCA) was used to determine the environmental factors that appeared to have the strongest influence on merA composition (Fig. 2). The symbols were mostly grouped according to fertilization practice, indicating that fertilization regimes influenced the merA gene diversity. In the CK treatment, it is likely that total $\mathrm{Hg}$ content had strong effect on the merA gene diversity pattern. The $\mathrm{NH}_{4}^{+}$and $\mathrm{NO}_{3}^{-}$contents had strongest effects on the merA gene diversity pattern in the N and NPK treatments, while the contents of organic matter, available $\mathrm{P}$ and $\mathrm{K}$ posed a strongest influence on the merA gene diversity pattern in the NPK + OM treatment.

\section{Phylogenetic analysis in the different treatments}

The phylogeny of merA sequences from the different treatments along with reference sequences from Genbank is shown in Fig. 3. The obtained 408 merA sequences yielded 31 merA phylotypes using a phylotype definition of $95 \%$ sequence identity. All the detected

Table 3. Comparison of the of merA library compositions between different treatments of a Chinese upland red soil.

\begin{tabular}{llll}
\hline & \multicolumn{3}{l}{$\begin{array}{l}\text { Sorensen similarity index (\%) } \\
\text { for the fertilization library }\end{array}$} \\
\cline { 2 - 4 } & $\mathrm{N}$ & NPK & NPK + OM \\
\hline CK & 43 & 33 & 0 \\
N & & 75 & 27 \\
NPK & & & 15 \\
\hline
\end{tabular}

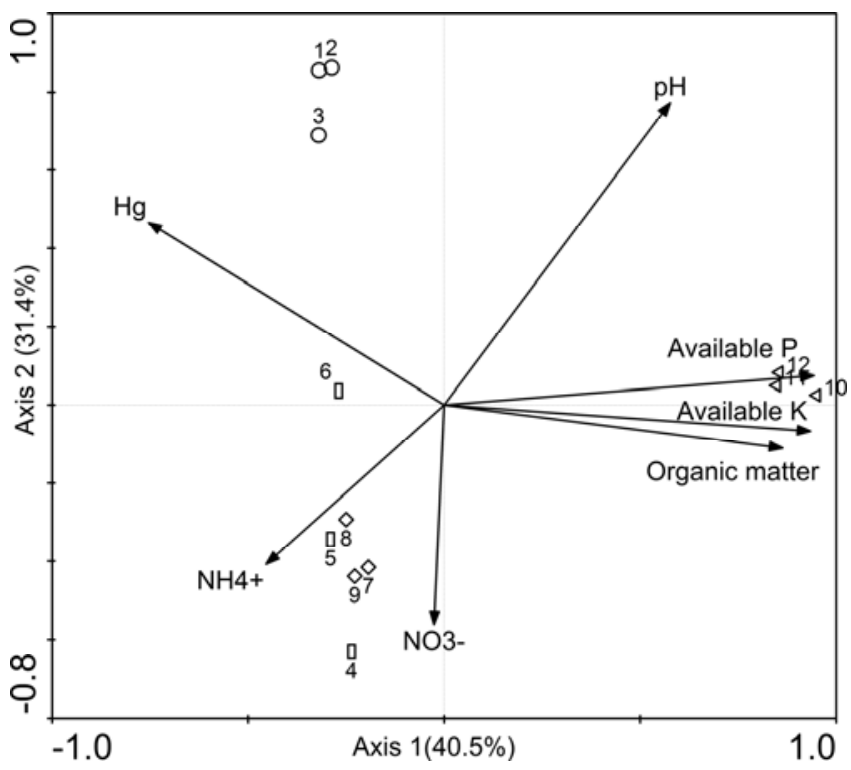

Figure 2. Canonical Correspondence Analysis (CCA) between the merA community and environmental variables of $\mathrm{pH}$ value, organic matter, total $\mathrm{Hg}$ content, $\mathrm{NH}_{4}^{+}, \mathrm{NO}_{3}^{-}$and available $\mathrm{P}$ and $\mathrm{K}$ in the soil. The meaning of symbols: circle represents CK treatment; box represents $\mathrm{N}$ treatment; diamond represents NPK treatment; lefttriangle represents NPK + OM treatment.

merA sequences were grouped into 7 distinct clusters. A total of 190 sequences in the twelve clone libraries were related to cultured mercury-resistance bacteria, and 167 sequences affiliated to the uncultured merA clone clusters from soil and sediment. Moreover, 51 merA sequences were grouped into unknown clusters.

The merA phylotypes in the four treatments were distinctly different. The proportion of sequence types representing various clusters in each treatment was calculated (Fig. 4). In the CK treatment, the merA gene was dominated by representatives of cluster 2 and 3, accounting for $83.3 \%$ (85/102) of the total phylotypes. All of detected sequences in the $\mathrm{N}$ treatment fell into cluster 1,4 and 7 , in which $52.9 \%(64 / 102)$ of sequences were grouped into uncultured bacterial clones. Sequences in the NPK + OM treatment were dominated by cluster 1 and the proportion reached $96.1 \%$ (98/102). The $\mathrm{N}$ and NPK treatments had several shared clusters, including mainly the merA gene representatives of cultured cluster 1 and uncultured cluster 7 related to the clones from sediment. No sequence affiliated with cluster 4 could be detected in the NPK and NPK + OM treatments.

\section{Discussion}

It is essential to investigate the diversity of $\mathrm{Hg}$ resistance gene that potentially modulates the toxicity of $\mathrm{Hg}$ 


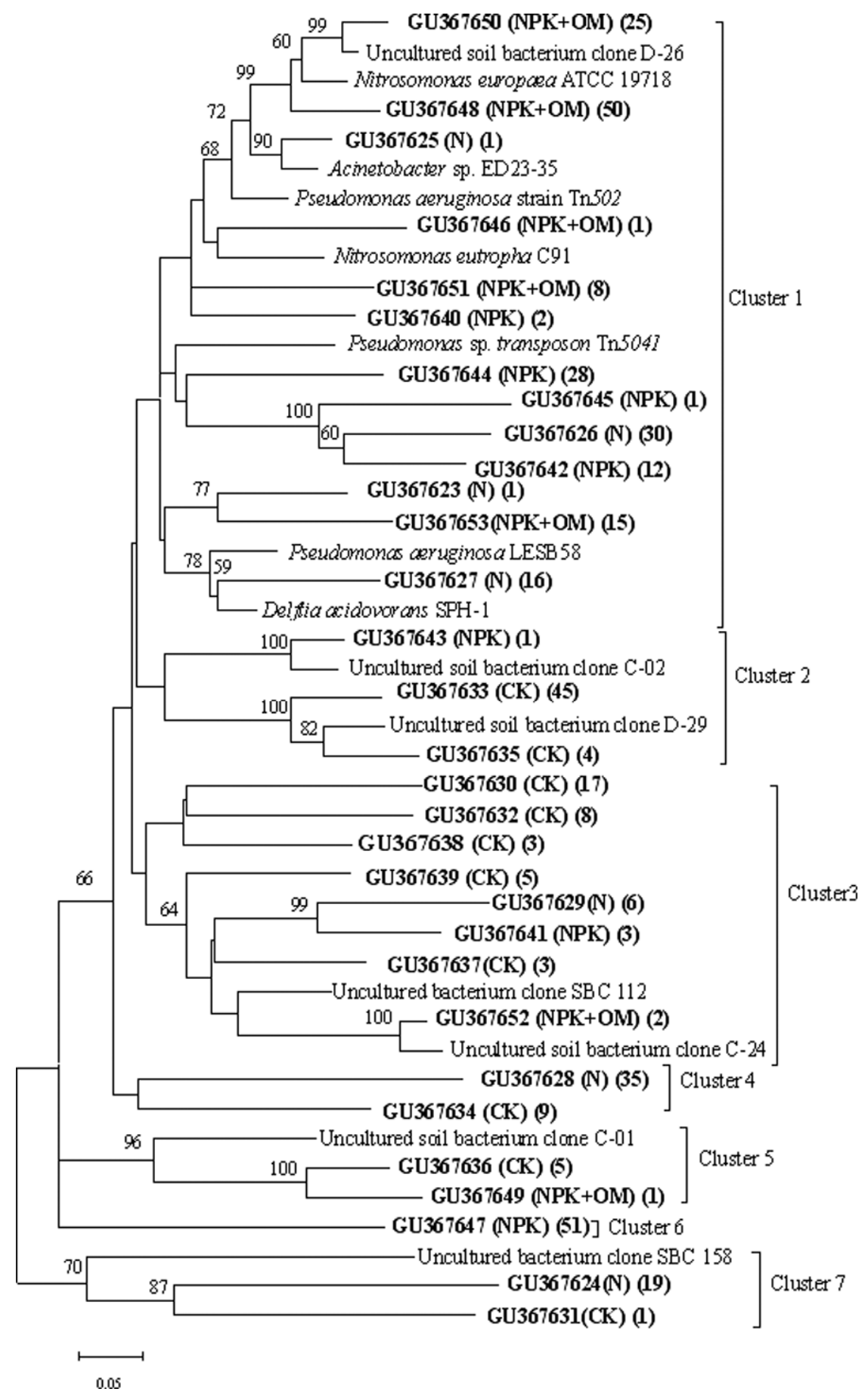

Figure 3. Neighbour-joining tree of merA DNA sequences. Bootstrap values $(>50 \%)$ are indicated at branch points. Designation of the clones in bold includes the following information: accession number in the GenBank with fertilization treatments in the parentheses. The number of clones in a particular phylotype is indicated in parentheses. The scale bar represents $5 \%$ estimated sequence divergence.

in the soils $[5,29]$, because it could provide a better understanding of soil environmental factors related to the $\mathrm{Hg}$ resistance microbes. In this study, twelve clone libraries were constructed for examining the merA gene diversity in the upland soils under long-term fertiliza- tion. Our results showed that some bacteria in these agricultural soils could have adapted to the long-term Hg stress.

This adaptation could partially involve the mechanisms: induction of enzymes related with the detoxifi- 
cation of $\mathrm{Hg}$ and the enrichment of populations carring $\mathrm{Hg}$ resistance trait $[8,30]$.

According to the results of this study, the soil environmental variables depending on the fertilization practices would play key roles in affecting the merA gene diversity pattern in these soils. The different environmental factors in the soils resulted from the different fertilizer applications. In the experimental plot, the CK treatment was considered to have not been disturbed by human activity and total soil $\mathrm{Hg}$ content in the soil could be regarded as a natural factor since its parent material source [25]. This non-anthropogenic factor was affecting the merA gene diversity in the CK treatment (Fig. 2), while only minor effect from it could be found in the other treatments with complex fertilizer applications. These results demonstrated that total $\mathrm{Hg}$ content, as a non-anthropogenic factor, should be important in impacting the merA gene diversity in these agricultural soils. However, anthropogenic fertilization effects were introduced and difference in merA gene diversity pattern was observed in the other fertilization treatments.

In general, long-term fertilizer applications could lead to a shift in soil physical and chemical property, thus the diversity pattern of soil microorganisms would be impacted. The results of CCA profile demonstrated that the merA gene diversity patterns were substantially influenced by the contents of $\mathrm{NH}_{4}^{+}$and $\mathrm{NO}_{3}^{-}$in positive effects and $\mathrm{pH}$ in negative effect. The effect was different in different fertilization treatments. So in Fig. 2 the symbols of merA gene diversity from the NPK + OM treatment were around organic matter, available $\mathrm{P}$ and available $\mathrm{K}$ content. This suggested that the merA gene diversity in the soil from the $\mathrm{NPK}+\mathrm{OM}$ treatment mainly depended on those environmental factors. In particular, the organic matter is a key impact factor in influencing the soil microorganisms $[23,24]$. The relatively lower Sorensen similarity index of merA library compositions between the NPK + OM treatment and the others indicated that it was the most different treatment from the others. This treatment did not have shared OTU with the CK treatment, highlighting the fact that long-term application of chemical fertilizers plus manures had sharply changed the merA gene diversity pattern probably involved with the much higher contents of organic matter, available $\mathrm{P}$ and $\mathrm{K}$ (Table 1). However, the merA gene diversity pattern in the soils from the $\mathrm{N}$ and NPK treatments could be controlled by the content of $\mathrm{NH}_{4}^{+}$and $\mathrm{NO}_{3}^{-}$according to the CCA profile, although the mechanism for this remained unclear. Furthermore, the merA gene diversity patterns in the $\mathrm{N}$ and NPK treatments exhibited similar trend, which was also supported by the high Sorensen similarity index $(75 \%)$ of the merA library compositions between them. Therefore, the status of merA gene diversity pattern in the soil was influenced by anthropogenic and non-anthropogenic factors together, and the different effects were found in the different treatments.

Many of the merA phylotypes reported here were related to those that thrived in other soils or sediments (Fig. 3). The 190 constituted merA sequences were closely to the phylotypes from Tn502, Tn5041 and Pseudomonas aeruginosa LESB58. The sequences related to Tn5041 merA phylotype has been detected not only in floodplain soil but also in an anaerobic enrichment of sediment $[17,18]$. Therefore, the $\mathrm{Hg}$ resistance bacteria carrying merA gene are broadly distributed in diverse environments. The 167 detected sequences affiliated to uncultured merA clone clusters, highlighting that the actual merA gene diversity in natural soil was vast compared with those recognized in culture collections. The remain 51 sequences were most closely related to putative merA gene of uncultured clones from floodplain soil and anaerobic sediment, suggesting that many mer $A$ genes were present in microbial community though they were difficult to isolate in laboratory. The shifts of merA gene diversity pattern were observed as a response to the different fertilizer practices (Fig. 4). The sequences of cluster 1 could be detected in all samples except the CK treatment, indicating the fertilizer application could be helpful to the growth of cultured mercuryresistance microorganisms. Moreover, the proportion of cluster 1 in the NPK + OM treatment is $97.3 \%$, which further demonstrated that balanced application of chemical fertilizers and organic manure could enhance the amount of culturable mercury-resistance microorganisms.



Figure 4. Proportions of merA phylotypes in the soils of four different fertilization treatments. 


\section{Concluding remarks}

The analysis of soil merA gene described here examined the effects of long-term fertilization on merA gene for the first time. As claimed by Zheng et al. [25], parent material was still the main factor affecting the total $\mathrm{Hg}$ content in the soil. Combined with results in this study, it could be inferred that total $\mathrm{Hg}$ content should be major factor contributing to the merA gene diversity in the soils without anthropogenic disturbance. When the long-term fertilization was performed in the field, the merA gene diversity in soil would be mainly influenced by environmental variables depending on the fertilizer application. The various merA gene diversity patterns between treatments solely indicated the potential reduction process of $\mathrm{Hg}$ by a group of bacteria which can thrive in this specifically treated agricultural soil. Considering the removal of crop biomass might cause minor change of total $\mathrm{Hg}$ in the soil, how these factors combined together to influence the $\mathrm{Hg}$ concentrations in the soil? Both in situ investigations and lab-incubation should be conducted further.

\section{Acknowledgements}

This work was supported by the National High Technology Research Program (2009AA06Z402), the Natural Science Foundation of China (40671172 and 50921064), and the Ministry of Environmental Protection of China (201009032 and 20082X07209-006-04). We are grateful to $\mathrm{B}$. R. Wang for assistance in soil sampling.

\section{References}

[1] Horvat, M., Nolde, N., Fajon, V., Jereb, V. et al., 2003. Total mercury, methylmercury and selenium in mercury polluted areas in the province Guizhou, China. Sci. Total. Environ., 304, 231-256.

[2] Meng, B., Feng, X.B., Qiu, G..L., Cai, Y. et al., 2010. Distribution patterns of inorganic mercury and methylmercury in tissues of rice (Oryza sativa L.) plants and possible bioaccumulation pathways. J. Agric. Food. Chem., 58, 49514958.

[3] Trevors, J.T., 1986. Mercury methylation by bacteria. J. Basic. Microbiol., 26, 499-504.

[4] Schaefer, J.K., Yagi, J., Reinfelder, J.R., Cardona, T. et al., 2004. Role of the bacterial organomercury lyase (MerB) in controlling methylmercury accumulation in mercurycontaminated natural waters. Environ. Sci. Technol., 38, 4304-4311.

[5] Haferburg, G., Kothe, E., 2007. Microbes and metals: interactions in the environment. J. Basic Microbiol., 47, $453-467$.
[6] Barkay, T., Miller, S.M., Summers, A.O., 2003. Bacterial mercury resistance from atoms to ecosystems. FEMS Microbiol. Rev., 27, 355-384.

[7] Barkay, T., Wagner-Döbler, I., 2005. Microbial transformations of mercury: potentials, challenges, and achievements in controlling mercury toxicity in the environment. Adv. Appl. Microbiol. Academic Press, pp. 1-52.

[8] de Lipthay, J.R., Rasmussen, L.D., Oregaard, G., Simonsen, K. et al., 2008. Acclimation of subsurface microbial communities to mercury. FEMS Microbiol. Ecol., 65, 145-155.

[9] Barkay, T., 1987. Adaptation of aquatic microbial communities to $\mathrm{Hg}^{2+}$ stress. Appl. Environ. Microbiol., 53, 2725-2732.

[10] Poulain, A.J., Ni, Chadhain, S.M., Ariya, P.A., Amyot, M. et al., 2007. Potential for mercury reduction by microbes in the high arctic. Appl. Environ. Microbiol., 73, 22302238.

[11] Silver, S., Phung, L.T., 1996. Bacterial heavy metal resistance: New surprises. Annu. Rev. Microbiol., 50, 753-789.

[12] Top, E.M., Springael, D., Boon, N., 2002. Catabolic mobile genetic elements and their potential use in bioaugmentation of polluted soils and waters. FEMS Microbiol. Ecol., 42, 199-208.

[13] Osborn, A.M., Bruce, K.D., Strike, P., Ritchie, D.A., 1997. Distribution, diversity and evolution of the bacterial mercury resistance (mer) operon. FEMS Microbiol. Rev., 19, 239-262.

[14] Vetriani, C., Chew, Y.S., Miller, S.M., Yagi, J. et al., 2005. Mercury adaptation among bacteria from a deep-sea hydrothermal vent. Appl. Environ. Microbiol., 71, 220-226.

[15] Schelert, J., Drozda, M., Dixit, V., Dillman, A., Blum, P., 2006. Regulation of mercury resistance in the crenarchaeote Sulfolobus solfataricus. J. Bacteriol., 188, 71417150.

[16] Ramond, J.B., Berthe, T., Duran, R., Petit F., 2009. Comparative effects of mercury contamination and wastewater effluent input on Gram-negative merA gene abundance in mudflats of an anthropized estuary (Seine, France): a microcosm approach. Res. Microbiol., 160, 10-18.

[17] Ramond, J.B., Berthe, T., Lafite, R., Deloffre, J. et al., 2008. Relationships between hydro sedimentary processes and occurrence of mercury-resistant bacteria (merA) in estuary mudflats (Seine, France). Mar. Pollut. Bull., 56, 11681176.

[18] Oregaard, G., Sorensen, S.J., 2007. High diversity of bacterial mercuric reductase genes from surface and subsurface floodplain soil (Oak Ridge, USA). ISME J., 1, 453467.

[19] Chadhain, S.M.N., Schaefer, J.K., Crane, S., Zylstra, G.J., Barkay, T., 2006. Analysis of mercuric reductase (merA) gene diversity in an anaerobic mercury-contaminated sediment enrichment. Environ. Microbiol., 8, 1746-1752.

[20] Ahamadou, B., Huang, Q.Y., Chen, W.L., Wen, S.L. et al., 2009. Microcalorimetric assessment of microbial activity in long-term fertilization experimental soils of southern China. FEMS Microbiol. Ecol., 70, 186-195.

[21] Liu, X.Z., Zhang, L.M., Prosser, J.I., He, J.Z., 2009. Abundance and community structure of sulfate reducing prokaryotes in a paddy soil of southern China under differ- 
ent fertilization regimes. Soil Biol. Biochem., 41, 687694.

[22] Ge, Y., Zhang, J.B., Zhang, L.M., Yang, M., He, J.Z., 2008. Long-term fertilization regimes and diversity of an agricultural affect bacterial community structure soil in northern China. J. Soils Sediments, 8, 43-50.

[23] He, J.Z., Shen, J.P., Zhang, L.M., Zhu, Y.G. et al., 2007. Quantitative analyses of the abundance and composition of ammonia-oxidizing bacteria and ammonia-oxidizing archaea of a Chinese upland red soil under long-term fertilization practices. Environ. Microbiol., 9, 2364-2374.

[24] Zheng, Y., Zhang, L.M., Zheng, Y.M., Di, H.J., He, J.Z., 2008. Abundance and community composition of methanotrophs in a Chinese paddy soil under long-term fertilization practices. J.Soils Sediments, 8, 406-414.

[25] Zheng, Y.M., Liu, Y.R., Hu, H.Q., He, J.Z., 2008. Mercury in soils of three agricultural experimental stations with long-term fertilization in China. Chemosphere, 72, 12741278.

[26] Chao, A., Lee, S.M., 1992. Estimating the number of classes via sample coverage. J. Am. Stat. Assoc., 87, 210-217.

[27] Magurran, A.E. (ed.), 1988. Ecological Diversity and Its Measurement. Princeton University Press, Princeton.

[28] Yergeau, E., Bokhorst, S., Huiskes, A.H.L., Boschker, H.T.S. et al., 2007. Size and structure of bacterial, fungal and nematode communities along an Antarctic environmental gradient. FEMS Microbiol. Ecol., 59, 436-451.

[29] Lovley, D.R., 2003. Cleaning up with genomics: Applying molecular biology to bioremediation. Nature Rev. Microbiol., 1, 35-44.

[30] Nazaret, S., Jeffrey, W.H., Saouter, E., Vonhaven, R., Barkay, T., 1994. MerA gene-expression in aquatic environments measured by message-RNA production and $\mathrm{Hg}$ (II) volatilization. Appl. Environ. Microbiol., 60, 4059-4065. 